\title{
Uncertainty of forest biomass carbon patterns simulation on provincial scale: A case study in Jiangxi Province, China
}

WANG Yifu ${ }^{1,2},{ }^{*}$ YUE Tianxiang ${ }^{1,2}$, LEI Yuancai ${ }^{3}$, DU Zhengping ${ }^{1}$, ZHAO Mingwei $^{4}$

1. State Key Laboratory of Resources and Environment Information System, Institute of Geographic Sciences and Natural Resources Research, CAS, Beijing 100101, China;

2. University of Chinese Academy of Sciences, Beijing 100049, China;

3. Chinese Academy of Forestry, Beijing 100091, China;

4. Anhui Center for Collaborative Innovation in Geographical Information Integration and Application, Chuzhou University, Chuzhou 239012, Anhui, China

\begin{abstract}
Forest vegetation carbon patterns are significant for evaluating carbon emission and accumulation. Many methods were used to simulate patterns of forest vegetation carbon stock in previous studies, however, uncertainty apparently existed between results of different methods, even estimates of same method in different studies. Three previous methods, including Atmosphere-vegetation interaction model 2 (AVIM2), Kriging, Satellite-data Based Approach (SBA), and a new method, High Accuracy Surface Modeling (HASM), were used to simulate forest vegetation carbon stock patterns in Jiangxi Province in China. Cross-validation was used to evaluate methods. The uncertainty and applicability of the four methods on provincial scale were analyzed and discussed. The results showed that HASM had the highest accuracy, which improved by $50.66 \%, 33.37 \%$ and $28.58 \%$, compared with AVIM2, Kriging and SBA, respectively. Uncertainty of simulation of forest biomass carbon stock was mainly derived from modeling error, sampling error and statistical error of forest area. Total forest carbon stock, carbon density and forest area of Jiangxi were $288.62 \mathrm{Tg}, 3.06 \mathrm{~kg} / \mathrm{m}^{2}$ and $94.32 \times 10^{9} \mathrm{~m}^{2}$ simulated by HASM, respectively.
\end{abstract}

Keywords: forest carbon stock; HASM; AVIM2; Kriging; Satellite-data Based Approach (SBA)

\section{Introduction}

Forest is the largest carbon pool of terrestrial ecosystem, containing more than $80 \%$ of global above-ground carbon (Dixon, 1994). However, it is controversial that forest is a carbon sink or a carbon source. As accumulating carbon from atmospheric $\mathrm{CO}_{2}$ via photosynthesis, forest is a carbon sink; on the other hand, climatic warming, deforestation and land

Received: 2015-09-23 Accepted: 2015-12-29

Foundation: National Fundamental R\&D Program of the Ministry of Science and Technology of the People's Republic of China, No.2013FY111600-4

Author: Wang Yifu (1990-), PhD Candidate, specialized in ecological modeling and system simulation.

E-mail: wangyf@1reis.ac.cn

"Corresponding author: Yue Tianxiang (1963-), PhD and Professor, E-mail: yue@1reis.ac.cn 
use change make forest a major carbon source in some areas (IPCC, 2007). Consequently, simulating dynamic forest biomass carbon patterns accurately is significant for demonstrating forest carbon sink and source worldwide and regionally.

Estimation of forest vegetation carbon stock is the basis of simulation of forest biomass carbon patterns. Methods for estimating forest vegetation biomass carbon stock on national and regional scale have been developed, e.g. mean biomass density method (Brown and Lugo, 1984, 1992), volume-derived method (Fang et al., 1998; Wang et al., 2001) and Satellite-data Based Approach (Piao et al., 2005; Tan et al., 2007; Yao et al., 2015). The volume-derived method is regarded as the reasonable and reliable method so far, which has been widely applied (Fang et al., 2001, 2007; Pan et al., 2004; Xu et al., 2007; Wang et al., 2009; Ren et al., 2011). Fang et al. (2001) declared that forest of China was a carbon source during 1949 to the late 1970s, yet a carbon sink during the late 1970s to the late 1990s. Improving the parameters based on Fang's study, Zhang et al. (2013) demonstrated Fang et al. overestimated China's forest biomass carbon stock, with a result of $6.24 \mathrm{Pg}$ during 2004 to 2008. Li H K et al. (2011) and Li X et al. (2011) estimated national and provincial carbon stock, with substituting for detailed carbon content values of different tree species.

In previous studies, the methods for simulating forest biomass or carbon patterns could be generalized as four forms:

(1) Vegetation dynamic models (e.g. CENTURY (Parton, 1987; Parton, 1993), FORESTBGC (Running, 1994), CEVSA (Cao and Woodward, 1998), LPJ-DGVM (Sitch et al., 2003; Zhao et al., 2014), and AVIM2 (Huang, 2005; Huang et al., 2008). These models simulate photosynthesis, respiration and carbon accumulation of vegetation and cycles of water, heat and nitrogen, based on relationships between growth and climatic factors, soil properties, and so on. Dynamic vegetation carbon stock on large temporal and spatial scale could be monitored accurately by vegetation dynamic models.

(2) Geo-statistical methods (e.g. Kriging (Sales et al., 2007)), is based on the fact that the carbon density of adjacent patterns are correlative. These methods are appropriate to simulate forest carbon stock in the case of adequate even-distributed sampling. Sales et al. (2007) simulated forest carbon stock pattern in Brazilian Amazon region by Kriging with external drift, with accuracy improved.

(3) Satellite-data Based Approach (Piao et al., 2005; Tan et al., 2007), is a method for simulating patterns of forest vegetation carbon stock via empirical models derived from measured biomass carbon samples and satellite data. Foody et al. (2003) developed empirical models derived from vegetation indexes (from Landsat TM data) for tropic forest biomass estimation at sites in Brazil, Malaysia and Thailand, and declared that the relationship between predicted and measured biomass differed markedly among sites. Piao et al. (2005) developed a regression model derived from NDVI (from the NOAA/AVHRR land dataset) and National Forest Resource Inventory database, and simulated national forest biomass carbon patterns in China.

(4) HASM (Yue, 2011), a new method of surface modelling based on the fundamental theorem of surfaces, has been successfully applied to DEM construction (Yue et al., 2007, 2010; Chen and Yue, 2010; Chen et al., 2013a,b), filling voids in the Shuttle Radar Topography Mission (SRTM) dataset (Yue et al., 2012), simulation of mean annual temperature and precipitation (Yue et al., 2011, 2013a, b; Zhao and Yue, 2014a, b) and modelling soil 
properties (Shi et al., 2011), soil pollution (Shi et al., 2009) and drivers of soil change (Shi et al., 2012). Sun et al. (2013) and Zhao et al. (2014) applied HASM to forest biomass and carbon stock monitoring, with improved accuracy.

However, the difference apparently existed between results of different methods, even results of the same method in different studies. In this study, four methods, including AVIM2, SBA, Kriging and HASM, were used to simulate patterns of forest vegetation carbon stock of Jiangxi Province of China. The uncertainty and applicability of the four methods on a provincial scale were analyzed and discussed.

\section{Data}

\subsection{Statistic data}

The statistic data is from Jiangxi Province section of National Forest Resource Inventory (NFRI) database for China, collected from 2004 to 2008. Forest stands biomass was estimated by a volume-derived method. The area weighted mean forest stands biomass of each forest stand type was calculated by Eq. (1):

$$
W=a \cdot V+b
$$

where $W$ is area weighted mean forest stands biomass $(\mathrm{Mg} / \mathrm{ha}), V$ is area weighted mean forest volume $\left(\mathrm{m}^{3} / \mathrm{ha}\right), a\left(\mathrm{Mg} / \mathrm{m}^{3}\right)$ and $b(\mathrm{Mg} / \mathrm{ha})$ are parameters related to biomass expression factor. Parameters $a$ and $b$ of all forest stand types are listed in Appendix 1 in Fang et al., 2007.

Biomass of economic forests, bamboo, woodlands and shrub forests were calculated by the mean biomass density method. The mean biomass density of economic forests was assumed to be $23.70 \mathrm{Mg} /$ ha (Fang et al., 1996); the mean biomass density of woodlands and shrub forests was assumed to be $19.76 \mathrm{Mg} / \mathrm{ha}$ (Fang et al., 1996); the mean biomass of single bamboo was assumed to be $22.5 \mathrm{~kg}$ (Nie, 1994), and the number per hectare was assumed to be 1831 (Li X et al., 2011).

Biomass of trees on non-forest lands were calculated as volume multiplied the ratio of biomass and volume, and the ratio was calculated as total biomass divided to total volume of forest stands.

Carbon stock of all forest types were calculated by Eq. (2):

$$
B C D=W \cdot C_{\mathrm{C}}
$$

where $B C D$ is forest biomass carbon density $(\mathrm{Mg} / \mathrm{ha}) ; C_{\mathrm{C}}$ is carbon content. $C_{\mathrm{C}}$ of all forest stand types are listed in Table 1 , and $C_{\mathrm{C}}$ of other forest types are assumed to be 0.5 .

Finally, the total forest biomass carbon stock of Jiangxi was calculated by Eq. (3):

$$
C S=\sum_{i=1}^{n}\left(A_{i}-B C D_{i}\right) \cdot 10^{-6}
$$

where $C S$ is total forest vegetation carbon stock of Jiangxi $(\mathrm{Tg}) ; A_{i}$ (ha) and $B C D_{i}(\mathrm{Mg} / \mathrm{ha})$ are area and biomass carbon density of the $i$ th forest type, respectively; $n$ is the number of forest type in Jiangxi.

\subsection{Measured data}

Measured dataset was collected from 2004 to 2008, for SBA, Kriging and HASM and vali- 
dation, including 1674 sample plots. The plots, whose area was $667 \mathrm{~m}^{2}$, were even-distributed across Jiangxi. The tree species was identified and the diameter at breast height (dbh, $\mathrm{cm}$ ) was measured for every tree with a dbh $>5 \mathrm{~cm}$, and tree height was measured for 3 to 5 average trees in each plot. Heights were estimated by height- iameter equations, for trees haven't measured in height. Biomass of each tree in plots was calculated via tree biomass empirical models (Table 2). Carbon stock of each tree was calculated as biomass multiplied by carbon content (Table 1 ). The carbon stock of each plot was the sum of carbon stock of all trees in
Table 1 C content of tree species (Li and Lei, 2010)

\begin{tabular}{lc}
\hline \multicolumn{1}{c}{ Tree species } & $C_{\mathrm{C}}$ \\
\hline Pinus massoniana & 0.4596 \\
Pinus densata & 0.5009 \\
Pinus elliottii & 0.4596 \\
Pinus taeda & 0.4596 \\
Cunninghamia lanceolata & 0.5201 \\
Coniferous mixed forest & 0.5101 \\
Broad-leaved and coniferous mixed forest & 0.4978 \\
Cinnamomum camphora & 0.4916 \\
Schima superba & 0.4916 \\
Liquidambar formosana & 0.4916 \\
Oaks & 0.5004 \\
Sassafras tzumu & 0.4848 \\
Eucalyptus robusta & 0.5253 \\
Populus & 0.4956 \\
Broad-leaved mixed forest & 0.4900 \\
\hline
\end{tabular}

Table 2 Biomass empirical models for each tree species ( $\mathrm{Li}$ et al., 2010). $W_{\mathrm{A}}, W_{\mathrm{R}}, W_{\mathrm{S}}, W_{\mathrm{Ba}}, W_{\mathrm{Br}}$ and $W_{\mathrm{L}}$ are biomass of aboveground, root, stem, bark, branch and leaf, respectively $(\mathrm{kg}) ; \mathrm{D}(\mathrm{cm})$ and $\mathrm{H}(\mathrm{m})$ are diameter at breast height and tree height, respectively; $a$ and $b$ are parameters.

\begin{tabular}{|c|c|c|c|c|}
\hline \multirow{2}{*}{ Species } & \multirow{2}{*}{ Components } & \multirow{2}{*}{ Model form } & \multicolumn{2}{|c|}{ Parameters } \\
\hline & & & $a$ & $b$ \\
\hline \multirow{2}{*}{ Pinus massoniana } & Aboveground & $W_{\mathrm{A}}=a\left(D^{2} H\right)^{b}$ & 0.0716 & 0.8572 \\
\hline & Root & $W_{\mathrm{R}}=W_{\mathrm{T}} / a$ & 6.2300 & \\
\hline \multirow{2}{*}{ Pinus elliottii } & Aboveground & $W_{\mathrm{A}}=a D^{b}$ & 0.0839 & 2.4409 \\
\hline & Root & $W_{\mathrm{R}}=a D^{b}$ & 0.0436 & 2.2288 \\
\hline \multirow{5}{*}{ Cunninghamia } & Stem & $W_{\mathrm{S}}=a\left(D^{2} H\right)^{b}$ & 0.0734 & 0.8626 \\
\hline & Bark & $W_{\mathrm{Ba}}=a\left(D^{2} H\right)^{b}$ & 0.0138 & 0.8446 \\
\hline & Branch & $W_{\mathrm{Br}}=a\left(D^{2} H\right)^{b}$ & 0.0005 & 1.2331 \\
\hline & Leaf & $W_{\mathrm{L}}=a\left(D^{2} H\right)^{b}$ & 0.0196 & 0.7897 \\
\hline & Root & $W_{\mathrm{R}}=a\left(D^{2} H\right)^{b}$ & 0.0431 & 0.7358 \\
\hline \multirow{4}{*}{ Cupressus funebris } & Stem & $W_{\mathrm{S}}=a\left(D^{2} H\right)^{b}$ & 0.1253 & 0.7330 \\
\hline & Branch & $W_{\mathrm{Br}}=a+b\left(D^{2} H\right)$ & 0.1374 & 0.0129 \\
\hline & Leaf & $W_{\mathrm{L}}=a+b\left(D^{2} H\right)$ & 0.0535 & 0.0100 \\
\hline & Root & $W_{\mathrm{R}}=a+b\left(D^{2} H\right)$ & -0.1604 & 0.0111 \\
\hline \multirow{5}{*}{$\begin{array}{l}\text { Oaks, Liquidambar } \\
\text { formosana, Schima } \\
\text { superba, Cinnamomum } \\
\text { camphora }\end{array}$} & Stem & $W_{\mathrm{S}}=a\left(D^{2} H\right)^{b}$ & 0.0440 & 0.9169 \\
\hline & Bark & $W_{\mathrm{Ba}}=a\left(D^{2} H\right)^{b}$ & 0.0230 & 0.7115 \\
\hline & Branch & $W_{\mathrm{Br}}=a\left(D^{2} H\right)^{b}$ & 0.0104 & 0.9994 \\
\hline & Leaf & $W_{\mathrm{L}}=a\left(D^{2} H\right)^{b}$ & 0.0188 & 0.8024 \\
\hline & Root & $W_{\mathrm{R}}=a\left(D^{2} H\right)^{b}$ & 0.0197 & 0.8963 \\
\hline \multirow{4}{*}{ Eucalyptus robusta } & Stem & $W_{\mathrm{S}}=a D^{b}$ & 0.0903 & 2.4482 \\
\hline & Branch & $W_{\mathrm{Br}}=a D^{b}$ & 0.0049 & 2.8178 \\
\hline & Leaf & $W_{\mathrm{L}}=a D^{b}$ & 0.0127 & 2.2684 \\
\hline & Root & $W_{\mathrm{R}}=W_{\mathrm{T}} / a$ & 7.4500 & \\
\hline \multirow{2}{*}{$\begin{array}{l}\text { Populus, Melia azeda- } \\
\text { rach, Sassafras tzumu }\end{array}$} & Aboveground & $W_{\mathrm{A}}=a\left(D^{2} H\right)^{b}$ & 0.0496 & 0.9525 \\
\hline & Root & $W_{\mathrm{R}}=W_{\mathrm{T}} / a$ & 3.8500 & \\
\hline
\end{tabular}


the plot.

\subsection{Forest type map}

The forest type map (Figure 1) applied in this study was obtained from 2 datasets: 1) GlobCover global land cover map for the period from December 2004 to June 2006, at a spatial resolution of $300 \mathrm{~m} \times 300 \mathrm{~m}$, includes 6 forest types and 4 mosaic types which might contain forest; 2) GLC2000 global land cover map for the period from November 1999 to December 2000, at a spatial resolution of $1 \mathrm{~km} \times 1 \mathrm{~km}$, includes 9 forest types and 2 mosaic types which might contain forest (Table 3). Dataset 1 was used as primary data, while dataset 2 was used to extract forest patterns from mosaic in dataset 1 .
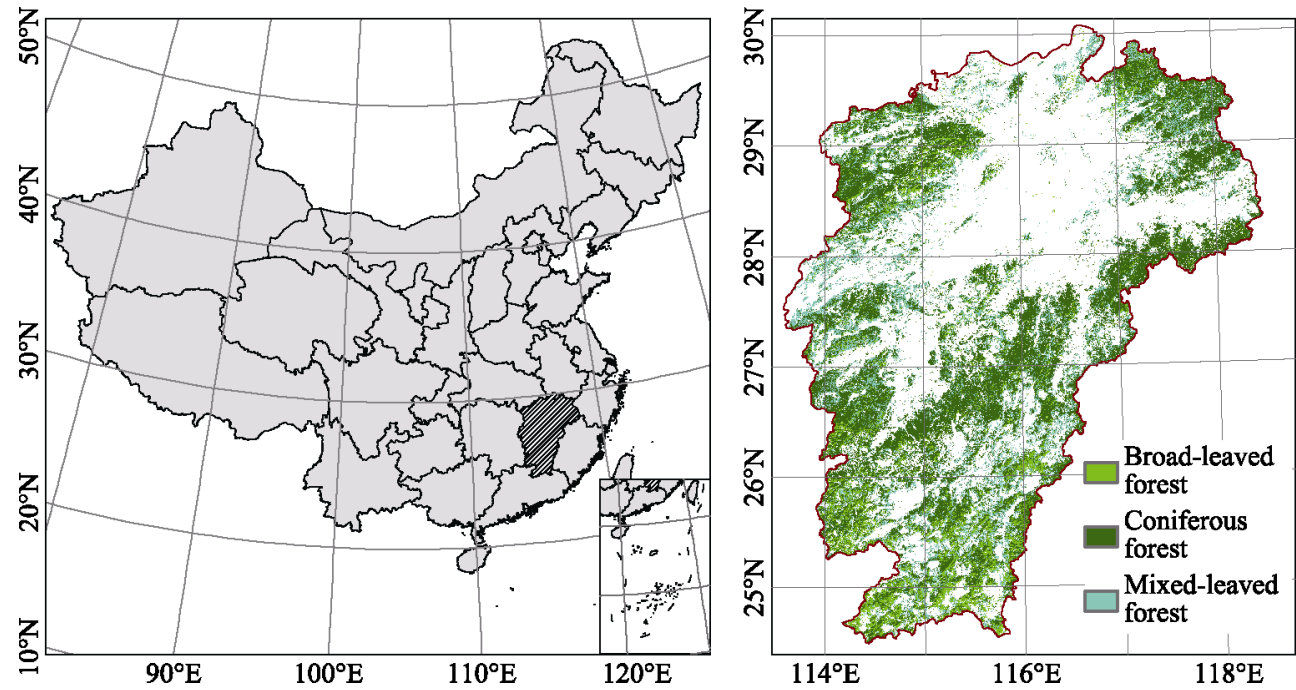

Figure 1 Location and distribution of forest in Jiangxi Province

Table 3 The forest types contained by two land cover maps (of China)

\begin{tabular}{|c|c|c|c|}
\hline \multicolumn{2}{|r|}{ GlobCover 2009 land cover map } & \multicolumn{2}{|r|}{ GLC2000 } \\
\hline Class & Class name & Class & Class name \\
\hline 20 & $\begin{array}{l}\text { Mosaic cropland }(50 \%-70 \%) / \text { vegetation (grass- } \\
\text { land/shrubland/forest) }(20 \%-50 \%)\end{array}$ & 1 & Tree cover: broad-leaved, evergreen \\
\hline 30 & $\begin{array}{l}\text { Mosaic vegetation (grassland/shrubland/forest) } \\
(50 \%-70 \%) / \text { cropland }(20 \%-50 \%)\end{array}$ & 2 & $\begin{array}{l}\text { Tree cover: broad-leaved, deciduous, } \\
\text { closed }\end{array}$ \\
\hline 40 & $\begin{array}{l}\text { Closed to open }(>15 \%) \text { broad-leaved evergreen or } \\
\text { semi-deciduous forest }(>5 \mathrm{~m})\end{array}$ & 3 & $\begin{array}{l}\text { Tree cover: broad-leaved, deciduous, } \\
\text { open }\end{array}$ \\
\hline 50 & Closed $(>40 \%)$ broad-leaved deciduous forest $(>5 \mathrm{~m})$ & 4 & Tree cover: needle-leaved, evergreen \\
\hline 60 & $\begin{array}{l}\text { Open }(15 \%-40 \%) \text { broad-leaved deciduous for- } \\
\text { est/woodland }(>5 \mathrm{~m})\end{array}$ & 5 & Tree cover: needle-leaved, deciduous \\
\hline 70 & Closed $(>40 \%)$ needle-leaved evergreen forest $(>5 \mathrm{~m})$ & 6 & Tree cover: mixed-leaved type \\
\hline 90 & $\begin{array}{l}\text { Open }(15 \%-40 \%) \text { needle-leaved deciduous or ever- } \\
\text { green forest }(>5 \mathrm{~m})\end{array}$ & 7 & $\begin{array}{l}\text { Tree cover: regularly flooded, fresh } \\
\text { water }\end{array}$ \\
\hline 100 & $\begin{array}{l}\text { Closed to open }(>15 \%) \text { mixed broad-leaved and } \\
\text { needle-leaved forest }(>5 \mathrm{~m})\end{array}$ & 8 & $\begin{array}{l}\text { Tree cover: regularly flooded, saline } \\
\text { water }\end{array}$ \\
\hline 110 & $\begin{array}{l}\text { Mosaic forest or shrubland }(50 \%-70 \%) / \text { grassland } \\
(20 \%-50 \%)\end{array}$ & 9 & $\begin{array}{l}\text { Mosaic: Tree cover / Other natural } \\
\text { vegetation }\end{array}$ \\
\hline 120 & $\begin{array}{l}\text { Mosaic grassland }(50 \%-70 \%) / \text { forest or shrubland } \\
(20 \%-50 \%)\end{array}$ & 10 & Tree cover: burnt \\
\hline
\end{tabular}




\section{Methods}

\subsection{AVIM2}

Atmosphere-vegetation interaction model 2 (AVIM2) contains 3 modules, including physical process module (PHY), physiological plant growth module (PLT) and soil carbon and nitrogen dynamics module (SOM). SOM can be coupled directly and timely with modules PHY, and PLT.

The climatic dataset used in the model was generated by HASM interpolation method (Yue et al., 2013a), based on the data collected at 49 climate stations located in Jiangxi with a 100-kilometer-buffer area, from 1951 to 2008. The forest type dataset used in the model was the forest type map obtained in 2.3 which contained 5 types: evergreen needle-leaved forest, deciduous needle-leaved forest, evergreen broad-leaved forest, deciduous broad-leaved forest and mixed-leaved forest. The soil texture dataset used in the model was Soil Texture Type Map of China, at a scale of 1:4,000,000. Vegetation respiration parameters and loss parameter for each vegetation type have been adjusted to forests of this province.

\subsection{Kriging}

Kriging (Krige, 1951) is a fundamental method in geostatistics, including Simple Kriging, Ordinary Kriging, Co-Kriging, Universal Kriging and Disjunctive Kriging (Kleijnen, 2009). Ordinary Kriging is the method used in this study, whose prediction equation expressed by Eq. (4):

$$
V_{0}=\sum_{i=1}^{n} \omega_{i} V_{i}
$$

where $V_{0}$ is the value to be estimated; $V_{i}$ is the value of the $i$ th available sample; $\omega_{i}$ is the weight to be estimated; $n$ is the number of available samples; and $\sum_{i=1}^{n} \omega_{i}=1$.

The difference between true value and the estimated value $\left(R_{0}\right)$ could be calculated by Eq. (5):

$$
\sigma\left(R_{0}\right)=c_{0,0}+\sum_{i=1}^{n} \sum_{j=1}^{n} \omega_{i} \omega_{j} c_{i, j}-2 \sum_{i=1}^{n} \omega_{i} c_{i, 0}
$$

where $c_{i, j}$ is the covariance of $V_{i}$ and $V_{j} ; c_{0,0}$ is the variance of $V_{0} ; c_{i, 0}$ is the covariance of $V_{i}$ and $V_{0}$.

Introducing the Lagrange parameter, $\mu$, into Eq. (5) and taking the first order derivative with respect to $\omega$ and $\mu$, respectively, the constrained minimization problem can be expressed by Eq. (6):

$$
\left[\begin{array}{cccc}
c_{1,1} & \cdots & c_{1, n} & 1 \\
\vdots & \ddots & \vdots & \vdots \\
c_{n, 1} & \cdots & c_{n, n} & 1 \\
1 & \cdots & 1 & 0
\end{array}\right] \cdot\left[\begin{array}{c}
\omega_{1} \\
\vdots \\
\omega_{n} \\
\mu
\end{array}\right]=\left[\begin{array}{c}
c_{1,0} \\
\vdots \\
c_{n, 0} \\
1
\end{array}\right]
$$

The weight matrix $\omega$ could be obtained by solving Eq. (6), then $V_{0}$ can be calculated by Eq. (4).

The available samples used in the method were the measured data described in 2.2. 


\subsection{Satellite-data Based Approach (SBA)}

An empirical model was developed derived from vegetation indexes, spectral reflectance and topographical factors in this study. The satellite-data applied was from Landsat TM5 (bands 1 to 5 and 7), obtained from 2004 to 2008, at a spatial resolution of $30 \mathrm{~m}$. The spectral reflectance was expressed by image intensity of each band which ranges from 0 to 255 . The DEM data used was from ASTER GDEM dataset, at a spatial resolution of $30 \mathrm{~m}$. Independent variables in the empirical model contains TM5 bands 1 to 5 and $7(B 1, B 2, B 3, B 4$, $B 5, B 7)$, normalized differential vegetation index $(N D V I)$, ratio vegetation index $(R V I)$, altitude (unit: $\mathrm{m}$ ), slope (unit: degree) and aspect (unit: degree). The value of NDVI was calculated as $(B 4-B 3) /(B 4+B 3)$. The RVI was calculated as $B 4 / B 3$. The values of altitude, slope and aspect were generalized from DEM dataset by ArcGIS software. The empirical model can be expressed as Eq. (7),

$$
\begin{aligned}
B C D= & -115.9485-6.6195 B 1+8.8045 B 2-5.8455 B 3+1.646 B 4-0.248 \text { B5 } \\
& -0.563 \text { B7 }+84.849 \text { NDVI }+81.5795 \text { RVI }-0.033 \text { Altitude }+0.007 \text { Aspect } \\
& -0.4825 \text { Alope, } R^{2}=0.309, \mathrm{P}<0.001
\end{aligned}
$$

\subsection{High Accuracy Surface Modeling (HASM)}

HASM is a more complex approach than the previous ones. If the surface can be expressed as $z=(x, y, f(x, y))$, then the first fundamental coefficients can be formulated as:

$$
\left\{\begin{array}{l}
E=1+f_{x}^{2} \\
F=f_{x} f_{y} \\
G=1+f_{y}^{2}
\end{array}\right.
$$

The second fundamental coefficients can be formulated as:

$$
\left\{\begin{array}{l}
L=\frac{f_{x x}}{\sqrt{1+f_{x}^{2}+f_{y}^{2}}} \\
M=\frac{f_{x y}}{\sqrt{1+f_{x}^{2}+f_{y}^{2}}} \\
N=\frac{f_{y y}}{\sqrt{1+f_{x}^{2}+f_{y}^{2}}}
\end{array}\right.
$$

These two coefficient sets must satisfy the following Gauss equation set,

$$
\left\{\begin{array}{l}
f_{x x}=\Gamma_{11}^{1} f_{x}+\Gamma_{11}^{2} f_{y}+\frac{L}{\sqrt{E+G-1}} \\
f_{x y}=\Gamma_{12}^{1} f_{x}+\Gamma_{12}^{2} f_{y}+\frac{M}{\sqrt{E+G-1}} \\
f_{y y}=\Gamma_{22}^{1} f_{x}+\Gamma_{22}^{2} f_{y}+\frac{N}{\sqrt{E+G-1}}
\end{array}\right.
$$

where $\Gamma_{11}^{1}=\frac{G E_{x}-2 F F_{x}+F E_{y}}{2\left(E G-F^{2}\right)}, \Gamma_{12}^{1}=\frac{G E_{y}-F G_{x}}{2\left(E G-F^{2}\right)}, \Gamma_{22}^{1}=\frac{2 G F_{y}-G G_{x}-F G_{y}}{2\left(E G-F^{2}\right)}, \quad \Gamma_{11}^{2}=$ 
$\frac{2 E F_{x}-E E_{y}+F E_{x}}{2\left(E G-F^{2}\right)}, \Gamma_{12}^{2}=\frac{E G_{x}-F E_{y}}{2\left(E G-F^{2}\right)}$ and $\Gamma_{22}^{2}=\frac{E G_{y}-2 F F_{y}+F G_{x}}{2\left(E G-F^{2}\right)}$ are the second kind of Christoffel symbols.

If $\left\{\left(x_{i}, y_{j}\right)\right\}$ is an orthogonal division of a computational domain and $h$ the simulation step length, the central point of lattice $\left(x_{i}, y_{j}\right)$ could be expressed as $(0.5 h+(i-1) h, 0.5 h+(j-1)$ $h)$, in which $i=0,1,2, \ldots, I, I+1$ and $j=0,1,2, \ldots, J, J+1$. If $f_{i, j}^{(n)}(n \geqslant 0)$ represents the iterants of $f(x, y)$ at $\left(x_{i}, y_{j}\right)$ in the $n$th iterative step, in which $\left\{f_{i, j}^{(0)}\right\}$ are interpolations based on sampling values $\left\{\bar{f}_{i, j}\right\}$. In terms of numerical mathematics (Quarteroni et al., 2000), the iterative formulation of the HASM master equation set can be expressed as (Yue et al., 2013b; Zhao and Yue, 2014a),

$$
\begin{aligned}
& \frac{-f_{i+2, j}^{(n+1)}+16 f_{i+1, j}^{(n+1)}-30 f_{i, j}^{(n+1)}+30 f_{i-1, j}^{(n+1)}-f_{i-2, j}^{(n+1)}}{12 h^{2}} \\
= & \left(\Gamma_{11}^{1}\right)_{i, j}^{(n)} \frac{f_{i+1, j}^{(n)}-f_{i-1, j}^{(n)}}{2 h}+\left(\Gamma_{11}^{2}\right)_{i, j}^{(n)} \frac{f_{i, j+1}^{(n)}-f_{i, j-1}^{(n)}}{2 h}+\frac{L_{i, j}^{(n)}}{\sqrt{E_{i, j}^{(n)}+G_{i, j}^{(n)}-1}} \\
& \frac{-f_{i, j+2}^{(n+1)}+16 f_{i, j+1}^{(n+1)}-30 f_{i, j}^{(n+1)}+30 f_{i, j-1}^{(n+1)}-f_{i, j-2}^{(n+1)}}{12 h^{2}} \\
= & \left(\Gamma_{22}^{1}\right)_{i, j}^{(n)} \frac{f_{i+1, j}^{(n)}-f_{i-1, j}^{(n)}}{2 h}+\left(\Gamma_{22}^{2}\right)_{i, j}^{(n)} \frac{f_{i, j+1}^{(n)}-f_{i, j-1}^{(n)}}{2 h}+\frac{N_{i, j}^{(n)}}{\sqrt{E_{i, j}^{(n)}+G_{i, j}^{(n)}-1}} \\
& \frac{f_{i+1, j+1}^{(n+1)}-f_{i+1, j}^{(n+1)}-f_{i, j+1}^{(n+1)}+2 f_{i, j}^{(n+1)}-f_{i-1, j}^{(n+1)}-f_{i, j-1}^{(n+1)}+f_{i-1, j-1}^{(n+1)}}{2 h^{2}} \\
= & \left(\Gamma_{12}^{1}\right)_{i, j}^{(n)} \frac{f_{i+1, j}^{(n)}-f_{i-1, j}^{(n)}}{2 h}+\left(\Gamma_{12}^{2}\right)_{i, j}^{(n)} \frac{f_{i, j+1}^{(n)}-f_{i, j-1}^{(n)}}{2 h}+\frac{M_{i, j}^{(n)}}{\sqrt{E_{i, j}^{(n)}+G_{i, j}^{(n)}-1}}
\end{aligned}
$$

where $E_{i, j}^{(n)}, F_{i, j}^{(n)}$ and $G_{i, j}^{(n)}$ are the iterants of the first fundamental coefficients at the $n$th iterative step; $L_{i, j}^{(n)}, M_{i, j}^{(n)}$ and $N_{i, j}^{(n)}$ represent the iterants of the second fundamental coefficients at the $n$th iterative step; $\left(\Gamma_{11}^{1}\right)_{i, j}^{(n)},\left(\Gamma_{11}^{2}\right)_{i, j}^{(n)},\left(\Gamma_{22}^{1}\right)_{i, j}^{(n)}$ and $\left(\Gamma_{22}^{2}\right)_{i, j}^{(n)}$ are the iterants of the Christoffel symbols of the second kind at the $n$th iterative step, which depend only upon the first fundamental coefficients and their derivatives.

The matrix formulation of HASM master equations can be respectively expressed as,

$$
\begin{aligned}
& \mathbf{A} \cdot \mathbf{z}^{(n+1)}=\mathbf{d}^{(n)} \\
& \mathbf{B} \cdot \mathbf{z}^{(n+1)}=\mathbf{q}^{(n)} \\
& \mathbf{C} \cdot \mathbf{z}^{(n+1)}=\mathbf{p}^{(n)}
\end{aligned}
$$

where $\mathbf{A}, \mathbf{B}$ and $\mathbf{C}$ represent coefficient matrixes of the first equation, the second equation and the third equation; $\mathbf{d}^{(n)}, \mathbf{q}^{(n)}$ and $\mathbf{p}^{(n)}$ are right-hand side vectors of the three equations respec- 
tively; $\quad \mathbf{z}^{(n+1)}=\left(f_{1,1}^{(n+1)}, \ldots, f_{1, J}^{(n+1)}, \ldots \ldots, f_{I, 1}^{(n+1)}, \ldots, f_{I, J}^{(n+1)}\right)^{T}=\left(z_{1}^{(n+1)}, \ldots, z_{J}^{(n+1)}, \ldots, z_{(I-1) \cdot J+1}^{(n+1)}, \ldots, z_{I \cdot J}^{(n+1)}\right)^{T}$ $f_{i, j}^{(n)}$ is the value of the $n$th iteration of $f(x, y)$ at grid cell $\left(x_{i}, y_{i}\right) ; z_{(i-1) \cdot J+j}^{(n+1)}=f_{i, j}^{(n+1)}$ for $1 \leqslant i \leqslant I, 1 \leqslant j \leqslant J$

If $\bar{f}_{i, j}$ is value of $z=f(x, y)$ at the $p$ th sampled point $\left(x_{i}, y_{i}\right), s_{p,(i-1) \times J+j}=1, k_{p}=\bar{f}_{i, j}$. There is only one non-zero element, 1 , in every row of the coefficient matrix, $S$, making it a sparse matrix. The solution procedure of HASM, taking the sampled points as its constraints, can be transformed into solving the following linear equation set in terms of least squares principle

$$
\left[\begin{array}{llll}
\mathbf{A}^{T} & \mathbf{B}^{T} & \mathbf{C}^{T} & \lambda \cdot \mathbf{S}^{T}
\end{array}\right]\left[\begin{array}{c}
\mathbf{A} \\
\mathbf{B} \\
\mathbf{C} \\
\lambda \cdot \mathbf{S}
\end{array}\right] \mathbf{z}^{(n+1)}=\left[\begin{array}{llll}
\mathbf{A}^{T} & \mathbf{B}^{T} & \mathbf{C}^{T} & \lambda \cdot \mathbf{S}^{T}
\end{array}\right]\left[\begin{array}{c}
\mathbf{d}^{(n)} \\
\mathbf{q}^{(n)} \\
\mathbf{p}^{(n)} \\
\lambda \cdot \mathbf{k}
\end{array}\right]
$$

The parameter $\lambda$ is the weight of the sampling points and determines the contribution of the sampling points to the simulated surface. $\lambda$ can be a real number, which means all sampling points have the same weight, or a sector, which means each sampling point has its own weight. An area affected by a sampling point in a complex region is smaller than in a flat region. Therefore, a smaller value of $\lambda$ is selected in a complex region and a bigger value of $\lambda$ is selected in a flat region.

Let $\quad \mathbf{W}=\left[\begin{array}{llll}\mathbf{A}^{T} & \mathbf{B}^{T} & \mathbf{C}^{T} & \lambda \cdot \mathbf{S}^{T}\end{array}\right]\left[\begin{array}{c}\mathbf{A} \\ \mathbf{B} \\ \mathbf{C} \\ \lambda \cdot \mathbf{S}\end{array}\right]$ and, $\mathbf{v}^{(n)}=\left[\begin{array}{llll}\mathbf{A}^{T} & \mathbf{B}^{T} & \mathbf{C}^{T} & \lambda \cdot \mathbf{S}^{T}\end{array}\right]\left[\begin{array}{c}\mathbf{d}^{(n)} \\ \mathbf{q}^{(n)} \\ \mathbf{p}^{(n)} \\ \lambda \cdot \mathbf{k}\end{array}\right]$, then

HASM has the following formulation,

$$
\mathbf{W} \cdot \mathbf{z}^{(n+1)}=\mathbf{V}^{(n)}
$$

In terms of Gauss-Codazii equation set, iteration stopping criterion of HASM is formulated as,

$$
\left(\varphi_{1 y}-\phi_{2 x}-\varphi_{2} P-\phi_{2} Q\right)^{2}+\left(\varphi_{2 x}-\phi_{1 y}-\varphi_{1} Q-\phi_{1} P\right)^{2}+\left(Q_{x}+P_{y}+\varphi_{1} \varphi_{2}-\phi_{1} \phi_{2}\right)^{2}<\mathrm{EI}
$$

where, $\varphi_{1}=\frac{L}{\sqrt{E}}, \varphi_{2}=\frac{L}{\sqrt{G}}, P=\frac{\sqrt{E_{y}}}{\sqrt{G}}, Q=\frac{\sqrt{G_{x}}}{\sqrt{E}}, \phi_{1}=\frac{M}{\sqrt{G}}, \phi_{2}=\frac{M}{\sqrt{E}} ;$ EI is the iteration stopping criterion of HASM determined by an application requirement for accuracy.

The steps of HASM for forest carbon stock simulation are summarized as follows: (1) build forest carbon density surface as an initial surface for HASM iteration process, derived from satellite-data and measured data; (2) calculate the first fundamental coefficients and the second fundamental coefficients as well as the Christoffel symbols of the second kind; (3) solve HASM equations via an iteration process, and obtained an approximate distribution surface of forest carbon; (4) repeat the iteration process until simulation accuracy is satisfied. 


\subsection{Model evaluation}

Cross-validation was applied for validation of Kriging, SBA and HASM in this study, which was comprised of four steps: (1) $5 \%$ of the sample points were removed for validation prior to model creation; (2) the patterns of forest carbon stock in Jiangxi were simulated at a spatial resolution of $300 \mathrm{~m} \times 300 \mathrm{~m}$ using the remaining $95 \%$ of the sample points; (3) mean absolute error (MAE) and mean relative error (MRE) were calculated using the $5 \%$ validation dataset; and (4) the 5\% validation dataset was returned to the pool of the available station for the next iteration, and another 5\% validation dataset was removed. This process was repeated until all of the sample points were used for validation at least one time. Cross-validation was not essential for validation of AVIM2, because no sample point was required in simulation process of AVIM2. MAE and MRE of AVIM2 were calculated using all sample points. The simulation error statistics for each sample point can be calculated by Eqs. (20)-(21):

$$
\begin{gathered}
M A E=\frac{1}{n} \sum_{i}^{n}\left|o_{i}-s_{i}\right| \\
M R E=\frac{M A E}{\frac{1}{n} \sum_{i}^{n}\left|o_{i}\right|}
\end{gathered}
$$

where $n$ is the number of validation samples, $o_{i}$ and $s_{i}$ are measured value and simulated value of the $i$ th validation sample.

\section{Result}

\subsection{Validation}

Comparison of measured and simulated forest carbon densities was displayed in Figure 2. The range of forest carbon densities simulated by AVIM2 $\left(0.54-8.64 \mathrm{~kg} / \mathrm{m}^{2}\right)$ was seriously different from measured data $\left(0.03-243.25 \mathrm{~kg} / \mathrm{m}^{2}\right)$. It was mainly caused by the fact that forests were assumed as mature forest in physiological plant growth module (PLT) and the difference caused by age was overlooked. Forest carbon density simulated by SBA was accordant to measured data when it was less than $150 \mathrm{~kg} / \mathrm{m}^{2}$, however, it was underestimated when greater than $150 \mathrm{~kg} / \mathrm{m}^{2}$. A good coincidence was found between measured data and results of Kriging and HASM.

The results of cross-validation were display in Table 4. The MAE and MRE of AVIM2 method were $2.63 \mathrm{~kg} / \mathrm{m}^{2}$ and $79.79 \%$, respectively. The MAE and MRE of SBA method were $1.90 \mathrm{~kg} / \mathrm{m}^{2}$ and $57.71 \%$, respectively. The MAE and MRE of Kriging method were $2.06 \mathrm{~kg} / \mathrm{m}^{2}$ and $62.50 \%$, respectively. The MAE and MRE of HASM method were 0.96 $\mathrm{kg} / \mathrm{m}^{2}$ and $29.13 \%$, respectively.

The accuracy of AVIM2 was lower than SBA, Kriging and HASM. The simulated distribution by AVIM2 was consistent with potential distribution of forest carbon stock, taking into account that the simulation process strongly related to climate and soil properties. In other words, the result simulated on large scale would be more accurate than that on provincial scale. The accuracies of SBA and Kriging approximated to each other, being about $60 \%$ of 

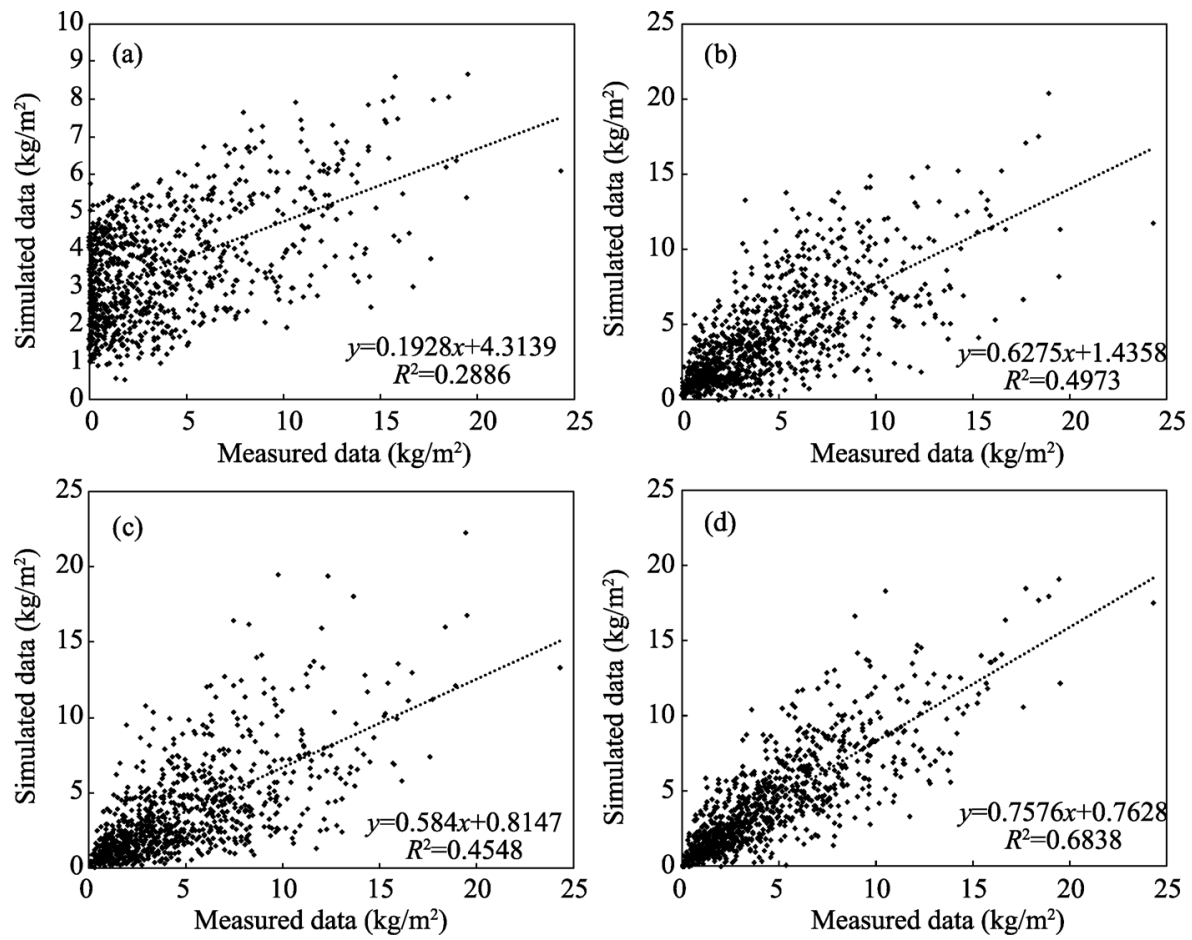

Figure 2 Comparison between observed and simulated results of forest vegetation C density (a. AVIM2; b. SBA; c. Kriging; d. HASM)

Table 4 The accuracy of the four methods for forest vegetation C stock pattern simulation of Jiangxi Province in China

\begin{tabular}{ccc}
\hline Methods & MAE $\left(\mathrm{kg} / \mathrm{m}^{-2}\right)$ & MRE $(\%)$ \\
\hline AVIM2 & 2.63 & 79.79 \\
Kriging & 2.06 & 62.50 \\
SBA & 1.90 & 57.71 \\
HASM & 0.96 & 29.13 \\
\hline
\end{tabular}

the MRE. HASM had the highest accuracy. Comparing with AVIM2, Kriging and SBA, the accuracy of HASM had improved by $50.66 \%$, $33.37 \%$ and $28.58 \%$, respectively.

The carbon stocks and carbon density of Jiangxi calculated by the four simulation methods were com-

pared with the result calculated by volume-derived method (Table 5). The results of simulation methods, except for AVIM2, were close to the results of volume-derived method. Particularly, the bias of SBA and HASM were less than $10 \%$.

\subsection{Total forest carbon stock of Jiangxi}

In previous studies, the definitions of forest vegetation carbon stock were inconsistent. In some studies, e.g. Fang et al. (2001), forest vegetation carbon stock was regarded as the carbon stock of forest stands; while in other studies, e.g. Zhang et al. (2013), it was treated as a sum of carbon stocks of forest stands, economic forests, bamboo, special shrubbery, woodlands and trees on non-forest lands. In this study, to avoid confusion, the first definition was considered as forest stand vegetation carbon stock (SCS), and the second definition was considered as forest vegetation carbon stock (CS), which contains SCS. Accordingly, the area weighted mean carbon stocks of forest and forest stand were forest vegetation carbon density (CD) and forest stand vegetation carbon density (SCD), respectively. 
Table 5 Comparison of forest vegetation C stocks of Jiangxi Province estimated by different methods $\left(\mathrm{Tg}=10^{12}\right.$ g). Forest vegetation $\mathrm{C}$ stocks include $\mathrm{C}$ stocks of forest stands, economic forests, woodlands, shrub forests, bamboos and trees in non-forest. $\mathrm{C}$ stocks of forest stands include $\mathrm{C}$ stocks of needle-leaved forests, broad-leaved forests and mixed-leaved forests.

\begin{tabular}{|c|c|c|c|c|c|c|}
\hline Methods & Components & $\begin{array}{c}\text { Area } \\
\left(10^{9} \mathrm{~m}^{2}\right)\end{array}$ & $\begin{array}{l}\text { Carbon } \\
\text { density } \\
\left(\mathrm{kg} / \mathrm{m}^{2}\right)\end{array}$ & $\begin{array}{c}\text { Carbon } \\
\text { stock } \\
(\mathrm{Tg})\end{array}$ & Periods & References \\
\hline Volume-derived & Forest stands & 78.93 & 2.72 & 214.70 & 2001-2005 & Li X et al., 2011 \\
\hline Volume-derived & Forest & 100.33 & 2.63 & 263.87 & 2001-2005 & Li X et al., 2011 \\
\hline Volume-derived & Forest stands & & 3.00 & & 2004-2008 & Li H K et al., 2011 \\
\hline Volume-derived & Forest & & & 289.07 & 2004-2008 & Li H K et al., 2011 \\
\hline Volume-derived & Forest & 99.80 & 2.67 & 297.97 & 2004-2008 & This study \\
\hline Volume-derived & Forest stands & 76.81 & 3.02 & 231.97 & 2004-2008 & This study \\
\hline Volume-derived & Needle-leaved forests & 47.05 & 2.60 & 122.33 & 2004-2008 & This study \\
\hline Volume-derived & Broad-leaved forests & 21.83 & 3.84 & 83.82 & 2004-2008 & This study \\
\hline Volume-derived & Mixed-leaved forests & 7.94 & 3.25 & 25.82 & 2004-2008 & This study \\
\hline Volume-derived & Economic forests & 12.03 & 1.19 & 14.26 & 2004-2008 & This study \\
\hline Volume-derived & Bamboos & 8.52 & 2.06 & 17.54 & 2004-2008 & This study \\
\hline Volume-derived & Woodlands & 0.45 & 0.99 & 0.44 & 2004-2008 & This study \\
\hline Volume-derived & Shrub forests & 1.99 & 0.99 & 1.96 & 2004-2008 & This study \\
\hline Volume-derived & Trees in non-forest & & & 31.80 & 2004-2008 & This study \\
\hline Volume-derived & Forest stands & 72.78 & 2.86 & 208.15 & 1999-2003 & This study \\
\hline AVIM2 & Forest & 94.32 & 3.71 & 349.93 & 2004-2008 & This study \\
\hline Kriging & Forest & 94.32 & 3.04 & 286.73 & 2004-2008 & This study \\
\hline SBA & Forest & 94.32 & 3.25 & 306.54 & 2004-2008 & This study \\
\hline HASM & Forest & 94.32 & 3.06 & 288.62 & 2004-2008 & This study \\
\hline HASM & Forest & 94.32 & 2.88 & 271.64 & 1999-2003 & This study \\
\hline
\end{tabular}

According to the results of volume-derived method, CS, CD and forest area of Jiangxi were $297.97 \mathrm{Tg}, 2.67 \mathrm{~kg} / \mathrm{m}^{2}$ and $99.80 \times 10^{9}$ $\mathrm{m}^{2}$, respectively; SCS, SCD and forest stand area of Jiangxi were $231.97 \mathrm{Tg}, 3.02 \mathrm{~kg} / \mathrm{m}^{2}$ and $76.81 \times 10^{9} \mathrm{~m}^{2}$, respectively. C stocks of needle-leaved forests, broad-leaved forests and mixed-leaved forests were 122.33, 83.82 and $25.82 \mathrm{Tg}$, respectively. C density of these three forest types were 2.60, 3.84 and 3.25 $\mathrm{kg} / \mathrm{m}^{2}$, respectively. Needle-leaved forest was the largest $\mathrm{C}$ pool, and broad-leaved forest had the highest $\mathrm{C}$ density in forest ecosystem in Jiangxi. C stock of economic forests, bamboos, woodlands, shrub forests and trees in non-forest were 14.26, 17.54, 0.44, 1.96 and $31.80 \mathrm{Tg}$, respectively.

Distribution of forest vegetation carbon stocks simulated by HASM was showed in Figure 3. Forest carbon stocks were equably

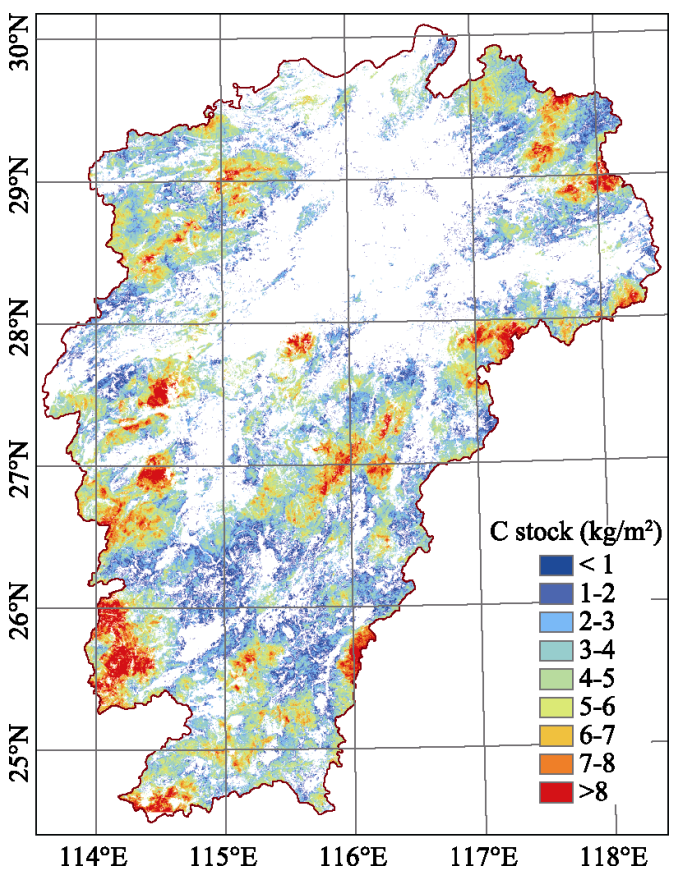

Figure 3 Forest vegetation $\mathrm{C}$ stock patterns simulated by HASM 
distributed in hilly and mountainous areas in eastern, western and southern parts of Jiangxi, while forest carbon density was low in basin areas, such as Ganzhou Basin and Yudu Basin.

\section{Discussion}

\subsection{Comparison with other studies}

SCD of Jiangxi Province in period from 2001 to 2005 was $2.72 \mathrm{~kg} / \mathrm{m}^{2}$, calculated by volume-derived method in Li X et al. (2011), which was lower than that both in period from 2004 to 2008 and in period from 1999 to 2003, calculated by the same method in this study. The difference was mainly due to inconsistency of the datasets used in two studies. The forest inventory data used in Li X et al. (2011) was from Provincial Forest Resource Inventory (PFRI), while that was from National Forest Resource Inventory (NFRI) in our study. For the different criterions, some woodlands, economic forests and trees in non-forest lands might be summed into forest stand in PFRI, causing that the area of forest stand of Jiangxi in PFRI $\left(78.93 \times 10^{9} \mathrm{~m}^{2}\right.$ in 2001 to 2005$)$ was larger than that in NFRI $\left(76.81 \times 10^{9} \mathrm{~m}^{2}\right.$ in 2004 to 2008 and $72.78 \times 10^{9} \mathrm{~m}^{2}$ in 1999 to 2003). On the account of lower carbon densities of woodlands, economic forests and trees in non-forest lands, SCD was underestimated in Li X et al. (2011). CD of the period from 2004 to 2008 calculated in our study $\left(3.02 \mathrm{~kg} / \mathrm{m}^{2}\right)$ was close to that in Li H K et al. (2011) $\left(3.00 \mathrm{~kg} / \mathrm{m}^{2}\right)$, because of the same method and same data applied in both studies.

In previous studies (Huang, 2005; Ji et al., 2008), AVIMs were applied in simulation of $N P P, N E P$ and biomass carbon stock on global and national scale. In Huang (2005), the simulated biomass of each forest type of China (including deciduous needle-leaved forests, evergreen needle-leaved forests, deciduous broad-leaved forests, evergreen broad-leaved forests and mixed-leaved forests) was consistent with CEVSA (Li et al., 2003) and Fang et al. (1996). However, it was insufficient in forest carbon stock pattern simulation on provincial scale in this study, which might be caused by the fact that the real distribution of forest carbon stock in Jiangxi deviated from the potential distribution, which the result of AVIM2 was consistent with. Forest distribution and forest carbon stock patterns obviously changed in some regions or provinces of China in the past 65 years. During 1949 to the late 1970s, forest was felled for reestablishment, which caused that the percentage of forest cover of Jiangxi decreased from $40.36 \%$ to $32.80 \%$. Since the late 1970 s, forest conservation and restoration projects were beginning to implement, as a result, the percentage of forest cover of Jiangxi increased to $58.32 \%$ in the early 21 st century. However, afforestation and introduction of exotic tree species disturbed the ecological succession, making the potential relationship between distribution of forest carbon stock and ecological factors indistinct. The dominant factors on forest growth changed from ecological factors (e.g. temperature, precipitation, soil properties) to management tactics (e.g. felling, forestation, introduction of exotic tree species) in Jiangxi.

Simulated CD by SBA $\left(3.25 \mathrm{~kg} / \mathrm{m}^{-2}\right)$ was overestimated in our study. The critical source of bias might be the empirical model which had a low accuracy $\left(R^{2}=0.309\right)$. In Piao et al. (2005), the $R^{2}$ of empirical model was 0.64 , and the simulated CD of China was very close to estimates in Fang et al. (2001) which was calculated by volume-derived method. The dif- 
ference of Piao et al. (2005) and our study was mainly due to the difference of datasets. In our study, satellite data was from TM dataset, at a spatial resolution of $30 \mathrm{~m} \times 30 \mathrm{~m}$, and the measured data was from sampling plots; while in Piao et al. (2005), satellite data was from the NOAA/AVHRR Land dataset, at a spatial resolution of $8 \mathrm{~km} \times 8 \mathrm{~km}$, and the measured data was from statistic data. The low resolution of satellite data and statistic data eliminate some variance. In Foody (2003), empirical models were built for tropical forest carbon stocks simulation of Thailand, Brazil and Malaysia, based on TM data and measured samples. The values of $R^{2}$ of empirical models were $0.300,0.318$ and 0.251 for Thailand, Brazil and Malaysia, respectively. The accuracies of Foody (2003) were close to our study, due to the similar dataset and same method.

\subsection{Uncertainties in simulations of forest carbon stock patterns}

\subsubsection{Mechanism of SBA, Kriging and HASM}

SBA is based on the relationship between biomass $\mathrm{C}$ density and factors, while Kriging is based on spatial autocorrelation of samples. Regarding longitude, latitude and $\mathrm{C}$ density as $x$, $y$ and $z$ axes, $C$ stock patterns could be regarded as a surface in three-dimensional space. The relationship between biomass $\mathrm{C}$ density and factors and the spatial autocorrelation of samples might be the external and internal characteristic of the surface, respectively.

Table 6 showed that $\mathrm{C}$ density was significant related to satellite data and geographic factors, which approved that SBA was a competent method for simulation of forest vegetation carbon stock patterns in macroscopic way. Predicted semi-variance (Eq. 22) indicated that spatial autocorrelation of samples was conspicuous, which approved that Kriging could be an appropriate method for simulation of forest vegetation carbon stock patterns in microscopic way. HASM considered both external characteristic (derived from satellite data and geographic factors) and internal characteristic (derived from samples) of the surface, and improved accuracy of simulation by fusing macroscopic and microscopic information.

Table 6 Correlation coefficient $(R)$ between biomass $\mathrm{C}$ density and factors. ${ }^{* *}$ means the factor was significantly correlated to biomass $\mathrm{C}$ density, $\mathrm{P}<0.01$.

\begin{tabular}{|c|c|c|c|c|c|c|c|c|c|c|c|}
\hline Factors & B1 & B2 & B3 & B4 & B5 & B7 & NDVI & RVI & Altitude & Aspect & Slope \\
\hline$R$ & $-0.210^{* *}$ & $-0.266^{* *}$ & $-0.254^{* *}$ & $0.242^{* *}$ & $-0.175^{* *}$ & $-0.213^{* *}$ & $0.219^{* *}$ & $0.229^{* *}$ & $-0.349^{* *}$ & 0.004 & $-0.331^{* *}$ \\
\hline
\end{tabular}

Even the accuracy of HASM had improved due to fusion of satellite data and sampling data, the models and the mechanism of HASM for simulation of forest carbon stock patterns should be further improved.

\subsubsection{Uncertainties in estimates of volume-derived method}

The estimates of volume-derived method were regarded as true values for simulations of forest carbon stock patterns. However, uncertainties confirmedly existed in field biomass data, empirical biomass-volume equations and assumed carbon contents (Zhang et al., 2013), which might induce errors in simulations. Even we collected carbon content of each species for carbon calculation, the main errors would still descend to simulations. 


\subsubsection{Effect of forest area on estimated CS}

The difference in calculated forest area was a significant cause of uncertainty of CS (or SCS) calculation. Comparing with Li X et al. (2011), forest stand area in period from 2004 to 2008 calculated in our study was underestimated. As a result, the SCS calculated in our study was lower than that in Li X et al. (2011), although the SCD was higher.

On the other hand, the confusion of area was a critical cause of the difference between the results of simulation methods and estimates of volume-derived method. Generally, the area in forest carbon stock patterns simulation contained the area of forest stand, bamboo, economic forests and some woodlands, while the measured sampling plots were only located at forest stands. In other words, bamboo, economic forests and some woodlands which have lower carbon density were regarded as forest stand in the process of simulation. Due to this reason, the simulated CD by HASM $\left(3.06 \mathrm{~kg} / \mathrm{m}^{-2}\right)$ was overestimated, while it was close to SCD calculated by volume-derived method $\left(3.02 \mathrm{~kg} / \mathrm{m}^{-2}\right)$.

\section{Conclusions}

This study simulated forest vegetation carbon stock patterns of Jiangxi Province using four simulation methods, including AVIM2, Kriging, SBA and HASM. The results were validated through cross-validation, and were compared with the estimates of volume-derived method. The main conclusions can be drawn as follows:

(1) HASM was the method which had the highest accuracy for forest vegetation carbon stock patterns simulation, followed by SBA, Kriging and AVIM2. AVIM2 is an appropriate method for simulating forest carbon stock distribution on large scale, yet not applicable for that on provincial scale. HASM improved accuracy by fusing macroscopic information from satellite data and microscopic information from measured data.

(2) CS, CD and forest area of Jiangxi calculated by volume-derived method were 267.31 $\mathrm{Tg}, 2.76 \mathrm{~kg} / \mathrm{m}^{-2}$ and $97.36 \times 10^{9} \mathrm{~m}^{2}$, respectively. They were $288.62 \mathrm{Tg}, 3.06 \mathrm{~kg} / \mathrm{m}^{-2}$ and $94.32 \times 10^{9} \mathrm{~m}^{2}$ by HASM, respectively. Compared with volume-derived method, the CS and CD were overestimated by HASM, due to confusing economic forests and bamboos with forest stands.

(3) Simulation errors of methods or models were the main source of uncertainty of forest carbon stock patterns simulation. In addition, two more causes induced the uncertainty: a) errors in estimates of volume-derived method which were regarded as true values in simulations descend to simulations; b) forest type maps were different in each study, causing inconsistence of forest area. And forest was confused with forest stands in some studies, causing inconsistence of forest carbon density.

\section{References}

Brown Sandra, Lugo Ariel E, 1984. Biomass of tropical forests: A new estimate based on forest volumes. Science, 223(4642): 1290-1293.

Cao Mingkui, Woodward F IaN, 1998. Net primary and ecosystem production and carbon stocks of terrestrial ecosystems and their responses to climate change. Global Change Biology, 4: 185-198.

Chen Chuanfa, Yue Tianxiang, 2010. A method of DEM construction and related error analysis. Computers \& Geosciences, 36: 717-725. 
Chen Chuanfa, Li Yanyan, Yue Tianxiang, 2013a. Surface modeling of DEMs based on a sequential adjustment method. International Journal of Geographical Information Science, 27: 1272-1291.

Chen Chuanfa, Yue Tianxiang, Dai Honglei et al., 2013b. The smoothness of HASM. International Journal of Geographical Information Science, 27: 1651-1667.

Dixon R K, Brown S, Houghton R A et al., 1994. Carbon pools and flux of global forest ecosystems. Science, 263: $185-188$.

Fan Zemeng, Li Jing, Yue Tianxiang, 2013. Land-cover changes of biome transition zones in Loess Plateau of China. Ecological Modelling, 252: 129-140.

Fang Jingyun, Chen Anping, Peng Changhui et al., 2001. Changes in forest biomass carbon storage in China between 1949 and 1998. Science, 292(5525): 2320-2322.

Fang Jingyun, Guo Zhaodi, Piao Shilong et al., 2007. Terrestrial vegetation carbon sinks in China, 1981-2000. Science in China Series D-Earth Sciences, 50(9): 1341-1350.

Fang Jingyun, Liu Guohua, Xu Songling, 1996, Biomass and net production of forest vegetation in China. Acta Ecologica Sinica, 16(5): 497-508. (in Chinese)

Fang Jingyun, Wang G Geoff, Liu Guohua et al., 1998. Forest biomass of China: An estimate based on the biomass-volume relationship. Ecological Applications, 8(4): 1084-1091.

Foody Giles M, Boyd Doreen S, Cutler Mark E J, 2003. Predictive relations of tropical forest biomass from Landsat TM data and their transferability between regions. Remote Sensing of Environment, 85(4): 463-474.

Huang Mei, 2005. Simulation of water, heat flux and carbon cycle of terrestrial ecosystem in China [D]. Beijing: Institute of Geographic Sciences and Natural Resources Research, CAS. (in Chinese)

IPCC, 2007. Climate Change 2007: Impacts, Adaptation, and Vulnerability. New York: Cambridge University Press.

Ji Jinjun, Huang Mei, Li Kerang, 2008. Prediction of carbon exchanges between China terrestrial ecosystem and atmosphere in 21 st century. Science in China, Series D-Earth Sciences, 51(6): 885-898.

Kleijnen Jack P C, 2009. Kriging metamodeling in simulation: A review. European Journal of Operational Research, 192(3): 707-716.

Krige D G, 1951. A statistical approach to some basic mine valuation problems on the Witwatersrand. The Journal of the Chemical, Metallurgical and Mining Society of South Africa, 52(6): 119-139.

Li Haikui, Lei Yuancai, Zeng Weisheng, 2011. Forest carbon storage in China estimated using forestry inventory data. Scientia Silvae Sinicae, 47(7): 7-12. (in Chinese)

Li Kerang, Wang Shaoqiang, Cao Mingkui, 2003. Vegetation and soil carbon stock of China. Science in China, Series D-Earth Sciences, 33(1): 72-80. (in Chinese)

Li Xin, Ouyang Xunzhi, Liu Qijing, 2011. Carbon storage of forest vegetation and its geographical pattern in China's Jiangxi Province during 2001-2005. Journal of Natural Resources, 26(4): 655-665. (in Chinese)

Nie Daoping, 1994. Structural dynamics of bamboo forest stands. Scientia Silvae Sinicae, 30(3): 201-208. (in Chinese)

Pan Yude, Birdsey Richard A, Fang Jingyun et al., 2011. A large and persistent carbon sink in the world's forests. Science, 333(6045): 988-993.

Pan Yude, Luo Tianxiang, Birdsey Richard A et al., 2004. New estimates of carbon storage and sequestration in China's forests: Effects of age-class and method on inventory-based carbon estimation. Climatic Change, 67(2/3): 211-236.

Parton W J, Schimel D S, Cole C V et al., 1987. Analysis of factors controlling soil organic-matter levels in great-plains grasslands. Soil Science Society of America Journal, 51(5): 1173-1179.

Parton W J, Scurlock J M O, Ojima D S et al., 1993. Observations and modeling of biomass and soil organic-matter dynamics for the grassland biome worldwide. Global Biogeochemical Cycles, 7(4): 785-809.

Piao Shilong, Fang Jingyun, Zhu Biao et al., 2005. Forest biomass carbon stocks in China over the past 2 decades: Estimation based on integrated inventory and satellite data. Journal of Geophysical Research-Biogeosciences, 
110(G1): 12 .

Ren Yin, Wei Xiaohua, Zhang Li et al., 2011. Potential for forest vegetation carbon storage in Fujian Province, China, determined from forest inventories. Plant and Soil, 345(1/2): 125-140.

Running Steven W, 1994. Testing forest: BGC ecosystem process simulations across a climatic gradient in Oregon. Ecological Applications, 4(2): 238-247.

Sales Marcio H, Souza Carlos M, Kyriakidis Phaedon C et al., 2007. Improving spatial distribution estimation of forest biomass with geostatistics: A case study for Rondonia, Brazil. Ecological Modelling, 205(1/2): $221-230$.

Shi Wenjiao, Liu Jiyuan, Du Zhengping et al., 2009. Surface modelling of soil pH. Geoderma, 150(1/2): 113-119.

Shi Wenjiao, Liu Jiyuan, Du Zhengping et al., 2011. Surface modeling of soil properties based on land use information. Geoderma, 162: 347-357.

Shi Wenjiao, Liu Jiyuan, Du Zhengping et al., 2012. Development of a surface modeling method for mapping soil properties. International Journal of Geographical Information Science, 2012, 22(4): 752-760.

Sitch S, Smith B, Prentice I C et al., 2003. Evaluation of ecosystem dynamics, plant geography and terrestrial carbon cycling in the LPJ Dynamic Global Vegetation Model. Global Change Biology, 9(2): 161-185.

Sun Xiaofang, Yue Tianxiang, Wang Qing, 2013. High accuracy surface modeling of grassland aboveground biomass. Journal of Remote Sensing, 17(5): 1060-1076. (in Chinese)

Tan Kun, Piao Shilong, Peng Changhui et al., 2007. Satellite-based estimation of biomass carbon stocks for northeast China's forests between 1982 and 1999. Forest Ecology and Management, 240(1-3): 114-121.

Wang Bin, Liu Moucheng, Zhang Biao, 2009. Dynamics of net production of Chinese forest vegetation based on forest inventory data. Forest Resource Management, 1: 35-43. (in Chinese)

Wang Xiaoke, Feng Zongwei, Ouyang Zhixun, 2001. The impact of human disturbance on vegetative carbon storage in forest ecosystems in China. Forest Ecology and Management, 148(1-3): 117-123.

Xu Xinliang, Cao Mingkui, Li Kerang, 2007. Temporal-spatial dynamics of carbon storage of forest vegetation in China. Progress in Geography, 26(6): 1-10. (in Chinese)

Yao Z Y, Liu J J, Zhao X W et al., 2015. Spatial dynamics of aboveground carbon stock in urban green space: A case study of Xi'an, China. Journal of Arid Land, 7(3): 350-360.

Yue Tianxiang, Du Zhengping, Song Dunjiang et al., 2007. A new method of surface modeling and its application to DEM construction. Geomorphology, 91: 161-172.

Yue Tianxiang, Tian Yongzhong, Liu Jiyuan et al., 2008. Surface modeling of human carrying capacity of terrestrial ecosystems in China. Ecological Modelling, 214(2-4): 168-180.

Yue Tianxiang, Song Dinjiang, Du Zhengping et al., 2010. High-accuracy surface modelling and its application to DEM generation. International Journal of Remote Sensing, 31(8): 2205-2226.

Yue Tianxiang, 2011. Surface Modelling: High Accuracy and High Speed Methods. New York: CRC Press.

Yue Tianxiang, Fan Zemeng, Chen Chuanfa et al., 2011. Surface modelling of global terrestrial ecosystems under three climate change scenarios. Ecological Modelling, 222(14): 2342-2361.

Yue Tianxiang, Zhao Na, Ramsey R Douglas et al., 2013a. Climate change trend in China, with improved accuracy. Climatic Change, 120(1/2): 137-151.

Yue Tianxiang, Zhao Na, Yang Hai et al., 2013b. The multi-grid method of high accuracy surface modelling and its validation. Trans GIS, 17(6): 943-952.

Zhang Chunhua, Ju Weimin, Chen Jing M et al., 2013. China's forest biomass carbon sink based on seven inventories from 1973 to 2008. Climatic Change, 118(3/4): 933-948.

Zhao Mingwei, Yue Tianxiang, Zhao Na et al., 2014. Combining LPJ-guess and HASM to simulate the spatial distribution of forest vegetation carbon stock in China. Journal of Geographical Sciences, 24(2): 249-268.

Zhao Na, Yue Tianxiang, 2014a. A modification of HASM for interpolating precipitation in China. Theoretical and Applied Climatology, 116: 273-285.

Zhao Na, Yue Tianxiang, 2014b. Sensitivity studies of a high accuracy surface modelling method. Science China-Earth Sciences, 57: 1-11. 